\title{
SECAGEM INTERMITENTE DE SOJA EM LEITO FIXO COM MODULAÇÃO DA VAZÃO DO AR NA ENTRADA DO SECADOR
}

\author{
R. O. DEFENDI ${ }^{1}$, P. R. PARAÍSO ${ }^{1}$, L. M. M. JORGE ${ }^{1 *}$ \\ ${ }^{1}$ Universidade Estadual de Maringá, Departamento de Engenharia Química \\ *e-mail: 1mmj@deq.uem.br
}

\begin{abstract}
RESUMO
A secagem intermitente é uma operação que trabalha com variações nas condições do ar de alimentação como vazão e temperatura, contrariamente à operação convencional cujas propriedades do ar são mantidas em valores constantes. Este tipo alternativo de operação visa melhorar o processo em termos de rendimento, de gasto energético ou de qualidade do material. Neste contexto, o objetivo deste trabalho foi avaliar a secagem intermitente de soja em leito fixo com a imposição da modulação da vazão do ar na entrada do secador e comparar estes resultados com os obtidos em operação com vazão constante. As comparações foram feitas em termos de rendimento do processo em relação à quantidade de água evaporada. Foi observado que por meio da operação com modulações periódicas da vazão do ar, a porcentagem de água evaporada foi maior que a porcentagem obtida em operação tradicional com 5\% de significância. Além disso, um modelo heterogêneo de secagem de grãos foi ajustado com base nos resultados obtidos. O modelo ajustado pôde razoavelmente descrever a secagem de soja em camada espessa sob a operação periódica e convencional.
\end{abstract}

\section{INTRODUÇÃO}

Um significante número de pesquisadores estudou a secagem intermitente de alguns materiais (CHIN e LAW, 2010; CHONG e LAW, 2011; CHUA et al., 2003; GOLMOHAMMADI et al., 2012; HERRITSCH et al., 2010; HOLOWATY et al., 2012; KOWALSKI e PAWOWSKI, 2010; MENEGHETTI et al., 2012; ONG et al., 2012; PUTRANTO et al., 2011; PUTRANTO e CHEN, 2012; PUTRANTO e CHEN, 2013). Um dos principais objetivos deste tipo de operação é minimizar o consumo energético, aumentar o rendimento do processo ou reduzir as perdas de qualidade do material (PUTRANTO et al., 2011; PUTRANTO e CHEN, 2012).

De acordo com Chua et al. (2003), a secagem intermitente é benéfica para materiais cuja secagem é controlada pela difusão interna de calor e umidade dentro do grão. A maioria dos produtos agrícolas como a soja e outros grãos possui esta característica. Neste contexto, a modulação das condições do ar como temperatura e vazão na entrada do secador pode proporcionar ganhos em termos de competitividade, economia, rendimento e qualidade.

Além disso, o processo de secagem pode danificar a qualidade dos produtos (PUTRANTO e CHEN, 2013), especialmente quando se opera em temperaturas muito altas. Assim, Chua et al. (2003) ainda acrescentam que esta variação de energia na entrada do secador devida a modulação da temperatura do ar é também benéfica para materiais sensíveis à variação de calor como comidas, ervas, temperos e medicamentos à base de 
plantas, pois o tempo em contato com ar em temperaturas altas é reduzido.

Em operação intermitente, podem ser moduladas várias condições do ar como a temperatura, vazão, pressão e umidade, as quais são propriedades que impactam nas taxas de secagem, na qualidade do material a ser seco e no consumo energético do processo.

Alguns estudos apontaram que a operação intermitente pode reduzir o tempo efetivo de secagem (CHIN e LAW, 2010; CHONG e LAW, 2011; HERRITSCH et al., 2010; ONG et al., 2012; THOMKAPANICH et al., 2007) e pode melhorar a qualidade do material seco (CHIN e LAW, 2010; CHONG e LAW, 2011; KOWALSKI e PAWOWSKI, 2010; ONG et al., 2012) em comparação com os resultados obtidos na operação convencional. Além disso, em alguns casos também foi possível reduzir o consumo energético (CHIN e LAW, 2010).

Neste contexto, o objetivo deste trabalho foi avaliar a secagem intermitente de soja em leito fixo com a imposição da modulação da vazão do ar na entrada do secador e comparar estes resultados com os obtidos em operação com vazão constante. As comparações foram feitas em termos de rendimento do processo em relação à quantidade de água evaporada no processo. Um tratamento estatístico foi usado para analisar se houve diferença significativa entre as médias das porcentagens de água evaporada das operações periódicas e convencionais. O método utilizado foi o teste $\mathrm{t}$ pareado descrito por Montgomery e Runger (2003). Além disso, com os resultados experimentais obtidos, um modelo heterogêneo de secagem de grãos foi ajustado.

\section{MATERIAIS E MÉTODOS}

\subsection{Materiais}

Os equipamentos e materiais utilizados foram um compressor que opera a $7 \mathrm{bar}$, um rotâmetro, um secador de leito fixo isolado com lã de $6 \mathrm{~cm}$ de diâmetro interno e $30 \mathrm{~cm}$ de comprimento, um psicrômetro digital, 17 termopares do tipo $\mathrm{K}$ (precisão de $\pm 2,2{ }^{\circ} \mathrm{C}$ ), um cronômetro, soja do tipo EMBRAPA 48 (diâmetro médio em torno de $6 \mathrm{~mm}$ ) fornecida pela COCAMAR, uma balança com leitura mínima de $0,01 \mathrm{~g}$, uma balança analítica com leitura mínima de 0,0001 g, um paquímetro digital, bolinhas de isopor e uma estufa que opera a $105^{\circ} \mathrm{C} \pm 2{ }^{\circ} \mathrm{C}$.

O sistema analisado é análogo ao utilizado por Fregolente et al. (2004). A posição dos termopares no leito está apresentada pela Tabela 1. No topo do secador, termopares anelares com cinco sensores de temperatura foram colocados analogamente ao estudo de Jorge et al. (2003).

Tabela 1 - Posição dos Termopares

\begin{tabular}{cccc}
\hline $\begin{array}{c}\text { Posição } \\
\text { no leito } \\
\text { (cm) }\end{array}$ & $\begin{array}{c}\text { Número de } \\
\text { Termopares }\end{array}$ & $\begin{array}{c}\text { Posição } \\
\text { no leito } \\
\text { (cm) }\end{array}$ & $\begin{array}{c}\text { Número de } \\
\text { Termopares }\end{array}$ \\
\hline 0,0 & 3 & 20,3 & 1 \\
5,3 & 1 & 23,3 & 1 \\
8,3 & 1 & 26,3 & 1 \\
11,3 & 1 & 29,3 & 1 \\
14,3 & 1 & 30,0 & 5 \\
17,3 & 1 & & \\
\hline
\end{tabular}

\subsection{Procedimento Experimental}

Primeiramente, ajustou-se a vazão do ar no valor desejado sem ligar sua linha na entrada do secador. A temperatura, a umidade absoluta e a umidade realtiva foram medidas tanto para o ar de secagem quanto para o ar ambiente. Em sequência, preencheu-se a base do leito com bolas de isopor que serviram como suporte ao leito de soja e ajudaram a uniformizar o fluxo de ar para evitar caminhos preferenciais. Além disso, o isopor apresenta alta inércia térmica e baixa absorção de umidade. Os trinta centímetros do leito do secador isolado foram preenchidos apenas com soja, cuja massa foi quantificada. Quatro amostras da soja utilizada foram levadas em 
estufa a $105{ }^{\circ} \mathrm{C} \pm 2{ }^{\circ} \mathrm{C}$ durante 24 horas a fim de se determinar o teor de umidade inicial. A umidade inicial média das amostras foi em torno de $20 \%$ em base seca.

Com o leito preenchido, a linha do ar de secagem foi plugada na entrada do secador e secou-se o material durante 1 hora. As temperaturas em cada termopar foram medidas ao longo do processo. O psicrômetro foi acoplado na saída do secador para medir a umidade absoluta e a temperatura do ar que deixa o leito. No final do processo, a massa de soja seca foi quantificada e quatro amostras foram levadas em estufa a $105{ }^{\circ} \mathrm{C} \pm 2{ }^{\circ} \mathrm{C}$ durante 24 horas para se determinar o teor médio de umidade final da soja.

A secagem foi realizada com o ar em temperatura constante e ambiente. Foram impostas modulações na vazão do ar entre dois valores fixos em intervalos constantes conforme a Tabela 2. A Figura 1 apresenta a forma como a modulação do ar foi realizada na entrada do secador.

Figura 1 - Modulação da Vazão do Ar

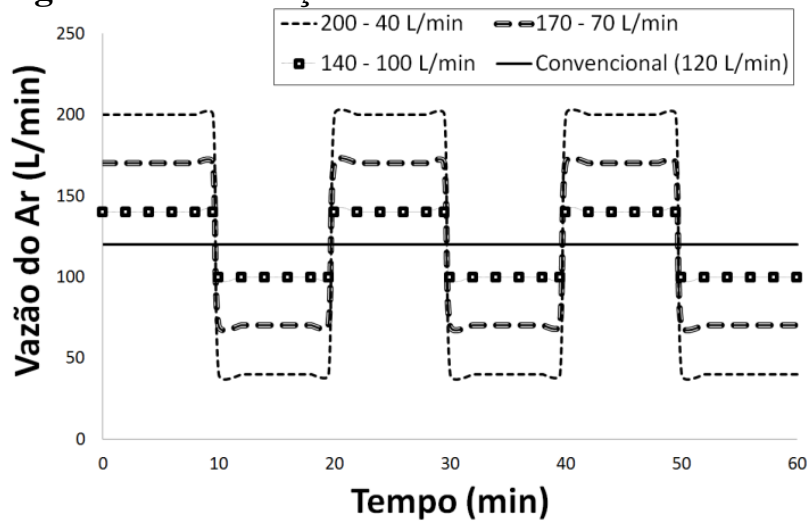

Para cada secagem periódica, uma secagem convencional (vazão do ar constante durante todo o processo) foi conduzida no mesmo dia para evitar interferências inerentes às condições climáticas nas análises comparativas entre os rendimentos de ambas as operações. As operações convencionais foram realizadas de forma a consumir $o$ mesmo tempo de secagem (uma hora) e a mesma demanda de ar (trabalhou-se com a vazão média da operação periódica, cujo valor foi de $120 \mathrm{~L} / \mathrm{min}$ ) em relação às quantidades obtidas de suas respectivas secagens periódicas. Os experimentos foram realizados em duplicata e em sequência randômica.

Tabela 2 - Modulação da Vazão na Entrada do Secador

\begin{tabular}{ccc}
\hline $\begin{array}{c}\text { Primeira / } \\
\text { Segunda } \\
\text { Posição da } \\
\text { Vazão (L/min) }\end{array}$ & $\begin{array}{c}\text { Intervalo } \\
\text { Entre Cada } \\
\text { Perturbação } \\
\text { (min) }\end{array}$ & $\begin{array}{c}\text { Número de } \\
\text { Perturbações }\end{array}$ \\
\hline A) $200 / 40$ & 10 & 6 \\
B) $40 / 200$ & 10 & 6 \\
C) $200 / 40$ & 30 & 2 \\
D) $200 / 40$ & 5 & 12 \\
E) $170 / 70$ & 10 & 6 \\
F) $140 / 100$ & 10 & 6 \\
\hline
\end{tabular}

\subsection{Modelo Heterogêneo}

O modelo ajustado neste trabalho é conhecido como modelo heterogêneo, ou de duas fases, ou ainda modelo de Michigan. As considerações adotadas deste modelo por uma significativa parte dos autores como Calçada (1994), Coutinho et al. (2009) e Defendi et al. (2014a) e que também foram assumidas neste trabalho são as seguintes:

- O volume da fase sólida é tomado como constante com o tempo.

- A variação da massa específica do sólido seco e do ar é negligenciada.

- Comportamento ideal para a fase gasosa, que é considerada apenas formada por ar e vapor de água.

- Desprezam-se a variação da porosidade do leito.

- Considera-se constante a viscosidade da fase gasosa com o tempo.

- O sólido seco e o líquido formam uma única fase homogênea.

- São constantes as velocidades de ambas as fases.

- Desprezam-se os fluxos radiais difusivos e condutivos, a radiação 
térmica, a dissipação viscosa, a compressibilidade da fase gasosa e as perdas de calor pelas paredes do sistema (sistema adiabático).

- Negligencia-se o acúmulo da fase fluida no sistema, uma vez comparada ao mesmo termo da fase sólida.

Com base nessas considerações, a variação da umidade do gás com a posição do leito em um sistema adiabático segundo Calçada (1994) é dada por:

$\frac{\partial Y_{g}}{\partial z}=\frac{f}{G_{g}}$

Em que Yg é a umidade do gás em base seca, z é a posição no eixo axial, f é a taxa de secagem por unidade de volume do leito de partículas e $\mathrm{G}_{\mathrm{g}}$ é o fluxo de ar. Essa equação representa um balanço de massa para a água presente na fase gasosa. $\mathrm{O}$ valor de $\mathrm{f}$ pode ser estimado pela seguinte equação:

$f=K_{s} a .\left(Y_{s}-Y_{s e}\right)$

Em que $\mathrm{Y}_{\mathrm{s}}$ é a umidade do sólido em base seca, $Y_{\mathrm{se}}$ é a umidade de equilíbrio do sólido em base seca e $\mathrm{K}_{\mathrm{s}} \mathrm{a}$ é o coeficiente volumétrico de transferência de massa. O valor de $\mathrm{K}_{\mathrm{s}}$ a foi obtido por meio da seguinte equação:

$\frac{K_{s} a}{\rho_{s s}}=K=\exp \left[-\left(A_{1}+A_{2} \cdot T g+A_{3} \cdot Y_{s 0}+\right.\right.$
$\left.\left.A_{4} \cdot Y_{S 0} \cdot T g\right) \cdot Y S^{A_{5}+A_{6} \cdot T g}\right] \cdot\left(A_{7} \cdot v\right)^{A_{8}}$

Em que $\mathrm{K}\left(\mathrm{s}^{-1}\right)$ foi denominado de coeficiente relativo de transferência de massa e $A_{i}$ são parâmetros do modelo a serem ajustados. $O$ formato da Equação 3 foi tomado com base no fato de que as cinéticas de secagem da soja tem caráter exponencial e é uma função da umidade inicial da soja e da temperatura do ar (DEFENDI et al., 2014b).

No balanço de energia na fase gasosa, observa-se que o calor sensível inerente a variação de temperatura do gás e do vapor na fase gasosa é igual ao calor trocado por convecção entre o gás e o sólido:

$G_{g} \cdot\left(c p_{a r}+Y_{g} \cdot c p_{v}\right) \cdot \frac{\partial T_{g}}{\partial z}=-h a\left(T_{g}-T_{s}\right)$

Onde $\mathrm{cp}_{\mathrm{ar}}$ é o calor específico do ar, $\mathrm{cp}_{\mathrm{v}}$ é o calor específico do vapor, $\mathrm{T}_{\mathrm{s}}$ é a temperatura do sólido e ha é o coeficiente de transferência de calor entre o sólido e o ar que pode ser obtido para sistemas de aquecimento e resfriamento de grãos segundo Boyce (1965) pela seguinte expressão:

$h a=A_{9} \cdot\left[\frac{G_{g} \cdot\left(T_{g}+273\right)}{P}\right]^{A_{10}}$

Onde $\mathrm{Tg}$ é dada em ${ }^{\circ} \mathrm{C}, \mathrm{G}_{\mathrm{g}}$ é dada em $\mathrm{kg} /\left(\mathrm{m}^{2} \cdot \mathrm{min}\right), \mathrm{P}$ é a pressão do sistema dada em Pa e ha é dado em $\mathrm{kJ} /\left(\mathrm{m}^{3} \cdot \mathrm{min} .{ }^{\circ} \mathrm{C}\right)$.

A umidade de equilíbrio da soja foi estimada pela seguinte equação (SILVA et al., 2008):

Para $0<\mathrm{UR}<55$ :

$Y_{S e}=\frac{A_{11} \cdot U R^{A_{12}}}{\ln \left[\operatorname{Tg}\left({ }^{\circ} F\right)\right]}$

Para $55<\mathrm{UR}<100$

$Y_{s e}=\frac{A_{13} \cdot e^{A_{14} \cdot U R}}{\ln \left[\operatorname{Tg}\left({ }^{\circ} F\right)\right]}$

Em que UR é a umidade relativa do ar (\%) e a temperatura do ar é dada em ${ }^{\circ} \mathrm{F}$.

A conservação de massa referente a variação da umidade do sólido é dada por:

$\frac{\partial Y_{S}}{\partial t}=-\frac{f}{(1-\varepsilon) \cdot \rho_{s S}}$

Onde $\mathrm{Y}_{\mathrm{s}}$ é a umidade do sólido em base seca, $\varepsilon$ é a porosidade média do leito e $\rho_{\mathrm{ss}}$ é a massa específica do sólido seco:

Por fim, o balanço de energia na fase sólida é dado pela seguinte expressão: 


$$
\begin{aligned}
& (1-\varepsilon) \cdot \rho_{s s} \cdot\left(c p_{s}+c p_{l} \cdot Y_{s}\right) \cdot \frac{\partial T_{s}}{\partial t}= \\
& h a\left(T_{g}-T_{s}\right)-f\left(c p_{v}\left(T_{g}-T_{s}\right)+\lambda\right)
\end{aligned}
$$

Os calores específicos do ar, da água e do vapor e o calor latente de vaporização da água foram estimados pelas equações da literatura de Perry e Green (1998). A massa específica do sólido seco e a porosidade do leito foram determinadas previamente, cujos valores respectivos foram $1174 \mathrm{~kg} / \mathrm{m}^{3}$ e 0,42 . Enquanto isso, o calor específico da soja foi determinado pela equação (MATA, DANTAS e BRAGA, 1999):

$C p s=0,391+0,461 \frac{Y s}{100+Y s}$

Em que Cps é dado em $\mathrm{cal} /\left(\mathrm{g}^{\circ} \mathrm{C}\right)$.

Para resolução do sistema de equações diferenciais tomaram-se as seguintes condições de contorno e iniciais:

- $\mathrm{Em} \mathrm{t}=0 \rightarrow \mathrm{Ts}=\mathrm{Ts}_{0}$

- $\mathrm{Em} \mathrm{t}=0 \rightarrow \mathrm{Ys}=\mathrm{Ys}_{0}$

- $\mathrm{Emz}=0 \rightarrow \mathrm{Tg}=\mathrm{Tga}$

- $\mathrm{Emz}=0 \rightarrow \mathrm{Yg}=\mathrm{Yga}$

Em que $\mathrm{Ts}_{0}, \mathrm{Ys}_{0}$, Tga e Yga são respectivamente a temperatura da soja inicial, a umidade da soja inicial, a temperatura de alimentação do gás e a umidade do gás de alimentação.

O modelo a duas fases foi resolvido numericamente pelo método da discretização das equações diferenciais por diferenças finitas para frente, gerando um sistema de equações resolvido sequencialmente.

\subsection{Ajuste dos Parâmetros}

Os parâmetros do modelo das Equações 3, 5, 6 e 7 foram ajustados com os dados da quantidade de água evaporada e dos dados de umidade e temperatura do ar para os experimentos em operação convencional e periódica. Ao total são 24 experimentos. A função objetivo minimizada durante o ajuste dos parâmetros foi a seguinte:

$$
\begin{aligned}
& \phi=\sum\left(\frac{\sqrt{\left(Y g_{\text {exp }}-Y g_{c a l}\right)^{2}}}{N o . Y g_{\text {exp }}}+\frac{\sqrt{\left(T g_{\text {exp }}-T g_{c a l}\right)^{2}}}{N o . T g_{\text {exp }}}+\right. \\
& \left.\frac{\sqrt{\left(m_{e v_{e x p}}-m_{e v_{c a l}}\right)^{2}}}{\text { No.men } m_{\text {exp }}}\right)
\end{aligned}
$$

Em que No é o número de observações e os subscritos exp e cal referem-se respectivamente aos valores obtidos experimentalmente e aos calculados pelo modelo.

Esta equação é uma adaptação do somatório dos mínimos quadrados, onde cada termo foi normalizado devido à diferença na ordem de magnitude entre as diferentes grandezas físicas. Os valores do qui-quadrado reduzido, da raiz do erro quadrático médio e da eficiência do modelo foram calculados para avaliar a qualidade do ajuste:

$$
\begin{aligned}
& \chi^{2}=\frac{\sum\left(Y g_{\text {exp }}-Y g_{\text {pre }}\right)^{2}}{N o-N c} \\
& R E Q M=\left(\frac{1}{N o} \sum\left(Y g_{\text {pre }}-Y g_{\text {exp }}\right)^{2}\right)^{1 / 2}
\end{aligned}
$$

$E F=\frac{\sum\left(Y g_{e x p}-\overline{Y g}_{\text {exp }}\right)^{2}-\sum\left(Y g_{p r e}-Y g_{\text {exp }}\right)^{2}}{\sum\left(Y g_{\text {exp }}-\bar{Y}_{\text {gexp }}\right)^{2}}$

$\chi^{2}$ é o qui-quadrado reduzido, REQM é a raiz do erro quadrático médio, EF é a eficiência do modelo, $\mathrm{Nc}$ é o número de constantes do modelo e $\overline{\mathrm{Yg}}_{\text {exp }}$ é o valor da umidade média experimental do ar. De acordo com Meisami-asl et al. (2010), o valor do quiquadrado reduzido determina o quão bom foi o ajuste e representa a raiz quadrada do desvio entre os dados experimentais e os calculados pelo modelo. Assim, o melhor valor para $\chi^{2}$ é o menor valor possível. Estes autores ainda acrescentam que o valor de REQM representa o desvio entre os valores experimentais e os 
estimados pelo modelo e EF está relacionada com a habilidade do modelo descrever o sistema. Idealmente, é interessante obter zero para o valor de REQM e 1,0 para o valor de EF. Os parâmetros estatísticos das Equações 11,12 e 13 estão em função de $\mathrm{Yg}$, mas eles também foram calculados em função de $\mathrm{Tg}$.

\section{RESULTADOS}

\subsection{Resultados Experimentais}

Observou-se que a operação periódica também mostrou ser vantajosa com base nas quantidades de água evaporada no processo. A Tabela 3 apresenta as porcentagens de água evaporada para cada operação, calculada pela quantidade de água evaporada (diferença entre a massa inicial e final do leito de soja) dividida pela quantidade de água inicial (estimada pelo teor de umidade inicial da soja). Destes resultados, notou-se que a quantidade relativa de água evaporada foi maior em operação periódica com modulação da vazão do ar na entrada do secador em comparação com os dados em operação convencional.

Este tipo de operação impacta na quantidade de água por massa de ar que vai sendo transportada ao longo do leito e impacta na temperatura ao longo do leito. Estas duas propriedades por sua vez influenciam nas taxas de secagem, uma vez que elas interferem nas transferências de massa e de energia e nas condições de equilíbrio. A Figura 2 mostra o perfil de umidade do ar na saída do secador para três diferentes tipos de amplitude entre as perturbações na vazão do ar. Nota-se que nesta figura foi construída apenas uma curva para a operação convencional (realizada a 120 $\mathrm{L} / \mathrm{min}$ ) referente ao experimento de modulação de 200 - $40 \mathrm{~L} / \mathrm{min}$, uma vez que as curvas das outras operações convencionais foram muito similares devido a vazão do ar ser a mesma e as temperaturas ambientes serem próximas.
Tabela 3 - Porcentagem de água evaporada

\begin{tabular}{ccc}
\hline \multicolumn{3}{c}{ Porcentagem de Água Evaporada $(\%)$} \\
\hline $\begin{array}{c}\text { Experimento } \\
\text { (Tabela 2) }\end{array}$ & $\begin{array}{c}\text { Operação } \\
\text { Periódica }\end{array}$ & $\begin{array}{c}\text { Operação } \\
\text { Convencional }\end{array}$ \\
\hline A & 27,9 & 23,2 \\
A & 26,0 & 22,9 \\
B & 26,6 & 23,3 \\
B & 24,0 & 21,5 \\
C & 28,8 & 24,3 \\
C & 24,7 & 22,3 \\
D & 28,5 & 24,4 \\
D & 23,3 & 20,3 \\
E & 29,9 & 23,6 \\
E & 25,3 & 21,2 \\
F & 26,4 & 21,6 \\
F & 22,5 & 19,1 \\
\hline
\end{tabular}

Desta figura, constata-se que quanto menor a velocidade do ar, mais altos são os níveis de umidade na saída do secador. Neste caso, não se pode dizer que quanto maior os níveis de umidade do ar na saída do secador maiores são as taxas de secagem, pois as vazões do ar alternaram. Quanto maior a vazão do ar, menos tempo este fica dentro do secador e menor é a quantidade de água por massa de ar que é transportada com o tempo. Quanto menor a vazão, maiores são as possibilidades de o ar saturar e quanto mais saturado o ar maiores são as pressões parciais do vapor de água no ar. Estes fatos dificultam o transporte de massa de água do grão para o ar, o que impacta numa redução das taxas de secagem.

Assim, em leito profundo a vazão (por consequência a velocidade também) do ar influencia nas taxas de secagem, pois esta altera os transportes de massa e de energia envolvidos entre o grão e o ar. A operação periódica foi mais vantajosa, pois houve indícios com base nas quantidades de água evaporada que as altas velocidades compensaram as baixas velocidades em comparação com a velocidade média tomada em operação convencional. Este resultado 
indica que as taxas de secagem não são linearmente dependentes da velocidade do ar.

Figura 2 - Umidade do ar na saída do secador

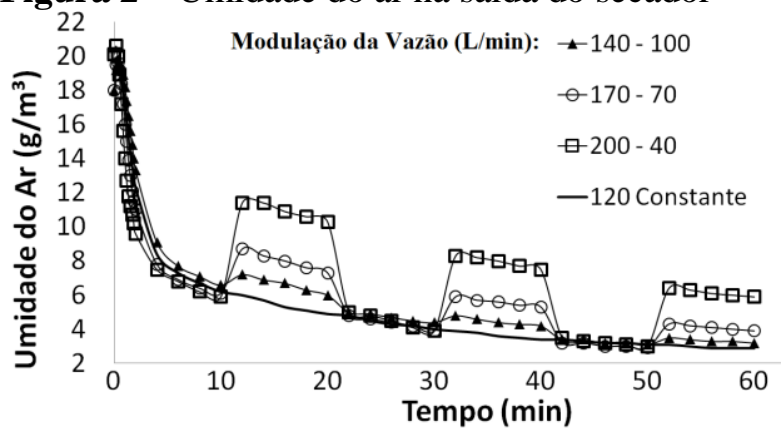

Outro fato interessante a ser avaliado é que a temperatura do leito decai em baixas vazões devido ao aumento da umidade do ar que vai aumentando ao longo do leito. Além disso, em baixas vazões a quantidade de ar dentro do leito é menor, o que reduz a quantidade de energia fornecida pelo ar. A Figura 3 apresenta a temperatura na entrada, no meio e na saída do leito para o experimento $\mathrm{C}$ da Tabela 2, onde o intervalo entre as perturbações da vazão de 200 e 40 $\mathrm{L} / \mathrm{min}$ foi de $30 \mathrm{~min}$. Verifica-se destes resultados que a operação periódica apresenta níveis de temperatura maiores nos trinta minutos iniciais do processo uma vez que sua vazão é maior e por consequência a umidade do ar é menor. Após os 30 minutos, quando a vazão em operação periódica é reduzida, a temperatura do meio do leito começa a reduzir devido ao aumento de umidade. Por outro lado, a temperatura do topo do leito leva em torno de 10 minutos para sentir o efeito da perturbação da vazão.

O teste estatístico pareado t descrito por Montgomery e Runger (2003) foi aplicado nas diferenças entre as porcentagens de água evaporada da operação periódica e convencional com o auxílio do Software R. Este método é ideal para amostras de pequenos tamanhos com variâncias desconhecidas e para observação de duas populações de interesse quando os dados coletados são feitos em pares e em condições homogêneas.

Figura 3 - Temperatura ao longo do leito

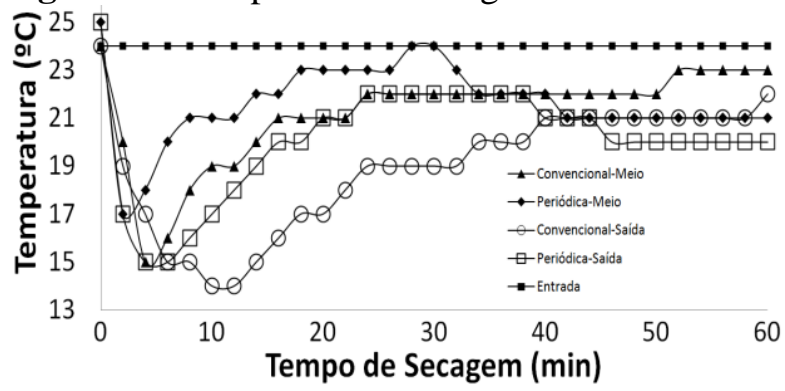

Para cada operação periódica, foi realizado um experimento em operação convencional conduzido no mesmo dia garantindo assim as mesmas condições climáticas. Além disso, ambas as operações foram conduzidas com a mesma amostra de soja (garantindo também a mesma umidade inicial). Assim, os experimentos foram realizados em condições homogêneas e coletados aos pares.

O teste apontou num nível de confiança de $95 \%$ que as operações periódicas e convencionais apresentam diferença significativa entre suas médias de porcentagem de água evaporada em condições de mesmo tempo de secagem e demanda de ar. O valor $\mathrm{p}$ obtido foi de $1,303 \cdot 10^{-07}$. A Figura 4 apresenta o diagrama de caixa para a distribuição das porcentagens de água evaporada, onde é possível observar também que há diferença entre as médias das operações.

Para se utilizar o teste pareado t, é necessário que as amostras tenham distribuição normal e que as amostras tenham variâncias homogêneas. O teste de ShapiroWilk indicou que as amostras tanto da operação periódica quanto da convencional apresentam distribuição normal com 5\% de significância resultando em valores $\mathrm{p}$ respectivamente de 0,9582 e de 0,6986. Além disso, o teste pela função var.test indicou com 
$5 \%$ de significância que a variância entre as amostras são iguais com o valor p de 0,2526.

Figura 4 - Diagrama de Caixa para a Porcentagem de Água Evaporada

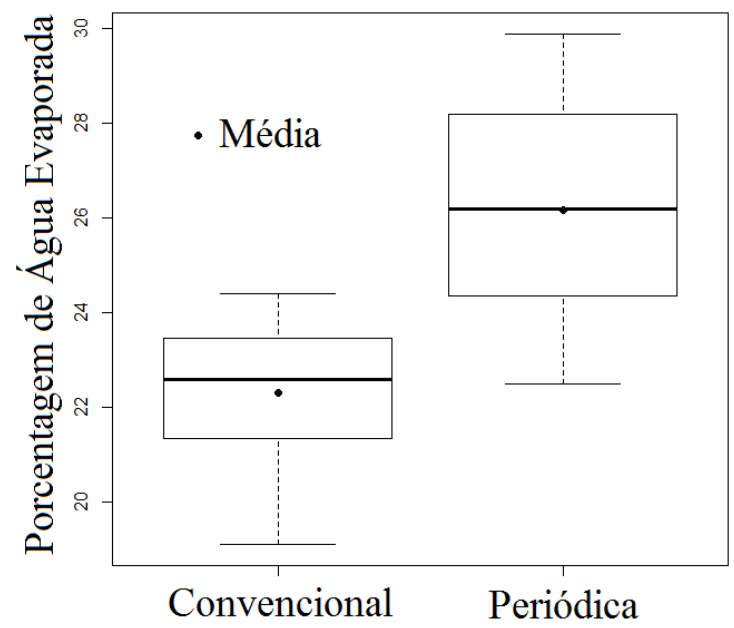

\subsection{Ajuste do Modelo}

A função objetivo minimizada com os dados das operações periódica e convencional resultou em 0,357. As Figuras 5 e 6 apresentam respectivamente os dados da temperatura e do teor de umidade obtidos pelo modelo em comparação aos obtidos experimentalmente. Foi possível observar que o modelo heterogêneo ajustado estimou a maioria dos dados experimentais com um desvio global menor que $20,0 \%$. Apenas $2,3 \%$ dos dados de temperatura e $8,5 \%$ dos dados de teor de umidade ficaram fora desta faixa de desvio.

Os valores dos parâmetros ajustados estão apresentados na Tabela 4 e as médias dos parâmetros estatísticos referentes à qualidade do ajuste estão resumidas na Tabela 5. Baseando-se nestes resultados e nos perfis dos gráficos, é possível inferir que o modelo heterogêneo ajustado pôde razoavelmente descrever a secagem de soja em camada espessa sob a operação periódica e convencional.
Figura 5 - Temperatura do Ar Estimada pelo Modelo

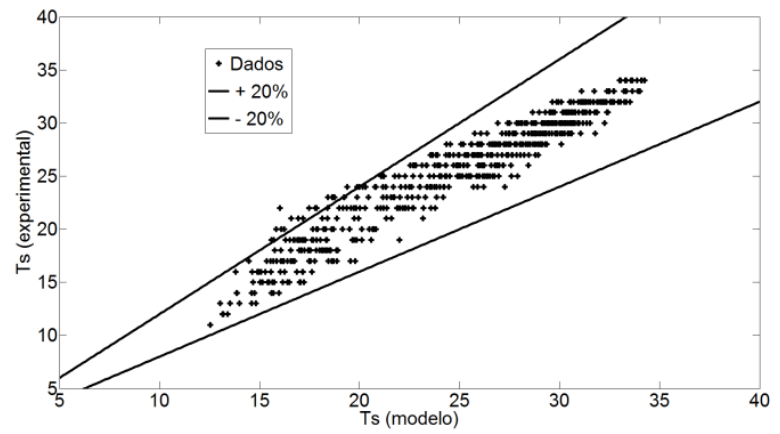

Figura 6 - Teor de Umidade do Ar Estimado pelo Modelo

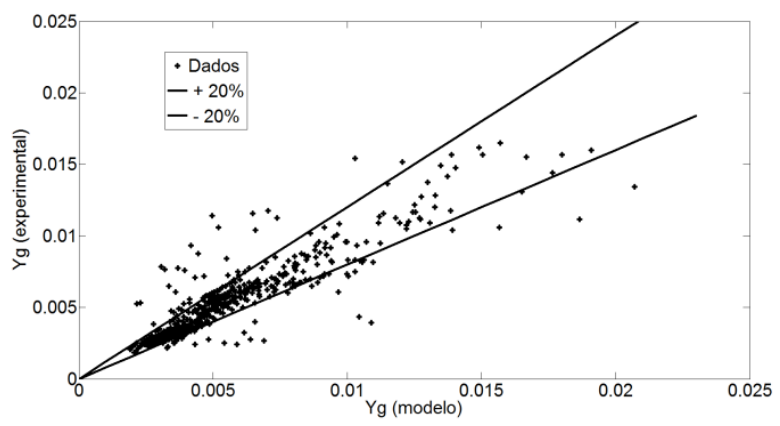

Tabela 4 - Parâmetros Ajustados

\begin{tabular}{cc}
\hline Parâmetros & Valor \\
\hline $\mathrm{A}_{1}$ & 0,01023 \\
$\mathrm{~A}_{2}$ & $-4,9018.10^{-4}$ \\
$\mathrm{~A}_{3}$ & 16,060 \\
$\mathrm{~A}_{4}$ & $-0,1737$ \\
$\mathrm{~A}_{5}$ & $-0,5965$ \\
$\mathrm{~A}_{6}$ & $-0,00743$ \\
$\mathrm{~A}_{7}$ & 0,4704 \\
$\mathrm{~A}_{8}$ & 0,3025 \\
$\mathrm{~A}_{9}$ & $1,1693.10^{4}$ \\
$\mathrm{~A}_{10}$ & 1,4376 \\
$\mathrm{~A}_{11}$ & $-0,00154$ \\
$\mathrm{~A}_{12}$ & 0,3206 \\
$\mathrm{~A}_{13}$ & $3,0587.10^{-4}$ \\
$\mathrm{~A}_{14}$ & 0,1535
\end{tabular}


Tabela 5 - Média dos Parâmetros Estatísticos

\begin{tabular}{ccc} 
Parâmetro & $\begin{array}{c}\text { Dados para } \\
\text { Umidade }\end{array}$ & $\begin{array}{c}\text { Dados para } \\
\text { Temperatura }\end{array}$ \\
\hline$\chi^{2}$ & $3,1918.10^{-6}$ & 5,2506 \\
REQM & 0,0014 & 1,7431 \\
EF & 0,7005 & 0,8325 \\
\hline
\end{tabular}

\section{CONCLUSÃO}

Observou-se que a operação periódica pode aumentar o rendimento do secador em comparação à secagem convencional em casos em que ambas as operações tiveram o mesmo tempo de secagem e demanda de ar. A modulação da vazão do ar na entrada do secador potencializou os transportes de massa e de energia envolvidos no processo, levando assim a maiores taxas de secagem. Testes estatísticos indicaram com 5\% de significância que a porcentagem de água evaporada em operação periódica foi maior em comparação aos resultados obtidos em operação convencional. Além disso, o modelo heterogêneo ajustado apresentou boa representatividade dos dados experimentais, cuja maioria pôde ser representada com um desvio global menor que $20,0 \%$

\section{REFERÊNCIAS}

BOYCE, D. S. Grain Moisture and Temperature Changes with Position and Time During Through Drying. J. Agric. Res., v.10, n. 4, p. 333-341, 1965.

CALÇADA, L. A. Modelagem e Simulação de Secadores em Leito Fixo. (Dissertação de Mestrado) PEQ/COPPE/UFRJ, Rio de Janeiro - RJ. 1994

CALÇADA, L. A.; BISCAIA Jr, E. C.; MASSARANI, G,. Secagem de Material Particulado: Modelo a Três Fases. Artigo
Publicado no anais do XXIV Congresso Brasileiro de Sistemas Particulados. 2002.

CHIN, S. K.; LAW, C. L. Product Quality and Drying Characteristics of Intermittent Heat Pump Drying of Ganoderma tsugae Murrill. Drying Technology, v. 28, p. 14571465, 2010.

CHONG, C. H.; LAW, C. L. Application of Intermittent Drying of Cyclic Temperature and Step-Up Temperature in Enhancing Textural Attributes of Dehydrated Manilkara zapota. Drying Technology, v. 29, n. 2, p. 245-252, 2011.

CHUA, K. J.; MUJUMDAR, A. S.; CHOU, $\mathrm{S}$. K. Intermittent drying of bioproducts - an overview. Bioresource Technology, v. 90, p. 285-295, 2003.

COUTINHO, M. R.; ROMERO, J. A. S.; CONCEIÇÃO, W. A. S., PARAÍSO, P. R.; JORGE, L. M. M. Secagem de Soja em Leito Fixo: Modelo a Duas Fases. XXXIV Congresso Brasileiro de Sistemas Particulados. ENEMP, 2009.

DEFENDI, R. O; SILVA, R. O.; SILVA, G. E. C.; PARAÍSO, P. R.; JORGE, L. M. M. Simulation and analysis of periodic and conventional drying of soybeans in fixed bed. Artigo Publicado nos anais do 19th International Drying Symposium. 2014a.

DEFENDI, R. O; SILVA, G. E. C.; PARAIISO, P. R.; JORGE, L. M. M. The initial grain moisture effect on soybean drying curves and mass transfer coefficients. Artigo Publicado nos anais do 19th International Drying Symposium. 2014b.

FREGOLENTE, L. V.; SANTOS, O. A. A.; JORGE, L. M. M. Estimativa das Propriedades Térmicas Efetivas de Grãos em um Secador de Leito Fixo. Ciência e 
Tecnologia de Alimentos, v. 24, n. 2, p. 270276, 2004.

GOLMOHAMMADI, M.; RAJABIHAMANE, M.; HASHEMI, S. J. Optimization of Drying-Tempering Periods in a Paddy Rice Dryer. Drying Technology, v. 30, n. 1, p. 106-113, 2012.

HERRITSCH, A.; DRONFIELD, J.; NIJDAM, J. J. Intermittent and Continuous Drying of Red Beech Timber From the Green Condition. Drying Technology, v. 28, p. 269277, 2010.

HOLOWATY, S. A.; RAMALLO, L. A.; SCHMALKO, M. E. Intermittent drying simulation in deep bed dryer of yerba maté. Journal of Food Engineering, v. 111, p. 110-114, 2012.

JORGE, L. M. M.; OLIVEIRA， G. P.; JORGE, R. M. M.; GIUDICI, R. Time constants determination and analysis for a ring-shaped temperature sensor in fixed bed. Acta Scientiarum. Technology, v. 25, n. 1, p. 9-15, 2003.

KOWALSKI, S. J.; PAWOWSKI, A. Drying of Wet Materials in Intermittent Conditions. Drying Technology, v. 28, n. 5, p. 636-643, 2010.

MATA, M. E. R. M. C.; DANTAS, L. A.; BRAGA, M. E. D. Programa Computacional Para Simulação de Secagem de Grãos. Revista Brasileira de Produtos Agroindustriais, v.1, n.1, p. 33-50, 1999.

MEISAMI-ASL, E.; RAFIEE, S.; KEYHANI, A.; TABATABAEEFAR, A. Determination of suitable thin layer drying curve model for apple slices (variety-Golab). Plant Omics Journal, v. 3, n. 3, p. 103-108, 2010.

MENEGHETTI, V. L.; AOSANI, E.; DA ROCHA, J. C.; DE OLIVEIRA, M.; ELIAS,
M. C.; POHNDORF, R. S. Mathematical models for intermittent drying of rice. Revista Brasileira de Engenharia Agrícola e Ambiental, v. 16, n. 10, p. 1115-1120, 2012.

MONTGOMERY, D. C.; RUNGER, G. C. Applied Statistics and Probability for Engineers; John Wiley \& Sons, Inc: United States of America, 2003.

ONG, S. P.; LAW, C. L.; HII, C. L. Optimization of Heat Pump-Assisted Intermittent. Drying Technology, v. 30, p. 1676-1687, 2012.

PUTRANTO, A.; XIAO, Z.; CHEN, X. D.; WEBLEY, P. A. Intermittent drying of mango tissues: implementation of the reaction engineering approach. Industrial \& Engineering Chemistry Research, v. 50, p. 1089-1098, 2011.

PUTRANTO, A.; CHEN, X. D. Multiphase modeling of intermittent drying using the spatial reaction engineering approach (SREA). Chemical Engineering and Processing: Process Intensification, v. 70, p. 169-183, 2013.

SILVA, J. de S; BERBERT, P. A.; AFONSO, A. D. L.; RUFATO, S. Qualidade dos Grãos. Secagem e Armazenagem de Produtos Agrícolas. Editora Aprenda Fácil. Segunda Edição. Viçosa, MG. 2008. p. 63 - 104.

\section{AGRADECIMENTOS}

O presente trabalho foi realizado com o apoio do Conselho Nacional de Desenvolvimento Científico e Tecnológico $\mathrm{CNPq}$ - Brasil e com o apoio da COCAMAR por ter disponibilizado soja Embrapa 48. 